\title{
A função social da escola em discussão, sob a perspectiva da educação inclusiva'
}

\author{
Débora Dainez ${ }^{2}$ \\ ORCID: 0000-0002-8223-098X \\ Ana Luiza Bustamante Smolka² \\ ORCID:0000-0002-2064-3391
}

\section{Resumo}

0 objetivo do presente estudo é problematizar a função social da escola no contexto das políticas de educação inclusiva, com base em um trabalho investigativo a respeito das práticas educativas e do processo de escolarização de dois alunos com deficiência, intelectual e múltipla. As discussões ancoram-se nas contribuições teórico-metodológicas da psicologia histórico-cultural que parte do pressuposto da natureza social do desenvolvimento humano e do papel da educação escolar no processo de constituição humana. A pesquisa de campo foi realizada em uma escola pública municipal do ensino fundamental de uma cidade do estado de São Paulo. Os registros em diário de campo e as videogravações do cotidiano da escola constituíram o material empírico para a análise, fornecendo elementos para se questionar os objetivos da educação escolar circunscritos ou restritos à socialização e ao trabalho de estimulação referentes aos alunos com deficiência. A análise destaca os modos e as possibilidades de participação dos alunos nas práticas educacionais e evidencia o desafio da escola em considerar as especificidades, tendo em vista as possibilidades de ensino-aprendizagem. Ao destacar o princípio da significação na elaboração histórica do conhecimento e ressaltando as diversas formas e condições de apropriação da cultura, o estudo aponta para a premência de se reconsiderar a função social da escola, de maneira a ampliar as possibilidades de conhecimento e desenvolvimento humano.

\section{Palavras-chave}

Desenvolvimento humano - Educação especial - Educação inclusiva - Escola pública.

1 - Este artigo refere-se a uma versão ampliada e reformulada de um texto apresentado e publicado nos Anais da 37a. Reunião Nacional da ANPED. Este trabalho recebeu apoio da Fundação de Amparo à Pesquisa do Estado de São Paulo (Fapesp). Processo 2014/07413-1. As autoras agradecem a leitura atenta e os pertinentes comentários da Profa. Dra. Mônica de Carvalho Magalhães Kassar, que contribuíram para apurar os argumentos do texto.

2 - Universidade Estadual de Campinas - (Unicamp), Campinas, SP, Brasil. Contato: ddainez@yahoo.com.br; asmolka@unicamp.br.

(i) (8) DOl: http://dx.doi.org/10.1590/S1678-4634201945187853

This content is licensed under a Creative Commons attribution-type BY-NC. 


\section{Challenging the social function of school, from the perspective of Inclusive Education*}

\section{Abstract}

This article aims at calling into question the social function of school within the context of Inclusive Education Policy. It is based upon research done on the educational practices and the schooling process of two particular students, one with intellectual disabilities, the other with multiple disabilities. This discussion is grounded in theoretical and methodological ideas belonging to historical and cultural psychology, which is based on the social nature of human development and also on the role of school education in human formative process. Field research was carried out in a state school in the municipal school network in a São Paulo state town. The empirical material for our analysis consisted of the records kept in a log book and also of the videotape recording of students' daily routine. The contents of such records enabled us to challenge the objectives of school education which are restricted to socialization and stimulation work done with students with disabilities. Our analysis focuses on the ways in which students participate in educational activities as well as the challenges faced by school when taking into account the particularities of each of these students as well as teaching and learning conditions in this environment. Our analysis focuses on the work done with signs and meanings within the educational process, and looks into the different paths taken towards cultural assimilation. Simultaneously, it points out to the need of calling into question the social function of school, aiming at expanding possibilities for people's learning and development.

\section{Keywords}

Human development - Special education - Inclusive education - State school.

\section{Introdução}

A educação escolar de crianças com deficiência tem constituído temática de grande relevância atualmente, pelos desafios e dilemas que coloca, tanto em termos das políticas públicas quanto em termos das práticas educativas cotidianas. Essa atenção está em pauta na agenda de pesquisas que enfocam a educação especial no contexto das políticas de educação inclusiva, ampliando o escopo das investigações a respeito das condições e das formas de acolhimento educacional de alunos com deficiência que passam a frequentar a instituição escolar.

\footnotetext{
* This article is an extended and revised version of a text presented and published in the annals of the 37th National Congress of the ANPED. Financial support for this article has been granted from Fundação de Amparo à Pesquisa do Estado de São Paulo - Process FAPESP 2014/07413. We wish to thank Professor Mônica de Carvalho Magalhães Kassar, whose thorough reading and useful comments have contributed to improve our manuscript.
} 
Os estudos nos campos da história da educação e da psicologia (SIEMS-MARCONDES; CAIAD0, 2013; ANACHE, 1997) têm nos mostrado como a categorização de deficiência, sobretudo de deficiência intelectual, foi constituindo-se a partir de um determinado modo, social e historicamente construído, de se conceber a inteligência e a cognição humana. Com isso, a marca da impossibilidade de educação devido à limitação intelectual subsidiou os processos de institucionalização, os quais não tinham uma finalidade formativa, mas de proteção, cuidado do indivíduo e controle social (JANNUZZI, 1985, 2006; BUENO, 2006).

Na década de 1980, no Brasil, foram publicados três estudos, hoje considerados clássicos na área da educação especial, que apontam para a importância de se considerar o problema da deficiência pelo prisma da educação. Em uma época marcada pela abertura do regime militar, os debates sobre a Constituição, a formação de entidades civis e a organização de educadores em busca de uma educação pública, laica, gratuita, democrática e de qualidade para todos, três pesquisadores - Isaías Pessotti, em Deficiência mental: da superstição à ciência (1984), Gilberta Jannuzzi, em A luta pela educação do deficiente mental no Brasil (1985), e Marcos Mazzotta, em Educação escolar comum ou especial (1987) - argumentam fortemente, em suas distinções e nuances, a favor de se deslocar a deficiência das áreas médicas e da assistência social para o campo educacional.

Ao contemplar o estatuto da educação em relação à criança com deficiência, e colocando em evidência seu compromisso social, os escritos supracitados, e com maior ênfase os trabalhos de Jannuzzi (1985, 2006), indicam a necessidade da construção de um sistema de ensino público consistente e articulado com um projeto político e educacional, sem cunho filantrópico, que contemple a formação humana integral dessa população.

Essa posição vai ao encontro da teoria histórico-cultural do desenvolvimento humano, tal como proposta por Vigotski (1995, 1996, 1997, 2000). Já no início do século $\mathrm{XX}$, o autor contestava os princípios educativos adotados em relação às crianças com deficiência baseados na impossibilidade de aprendizagem pela existência do déficit orgânico. Além disso, questionava a organização do ensino, que separava uma pedagogia especial de uma pedagogia geral. Ao considerar a educação - aí incluído o ensino escolar - como constitutiva do desenvolvimento, Vigotski (1997) argumentava, em seus escritos marcados pelo compromisso de transformação social, que o ensino da criança com deficiência deveria se ancorar nos mesmos princípios de desenvolvimento humano - de desenvolvimento cultural, como ele insistia em ressaltar - de qualquer pessoa.

Ao assumir que o homem é "um agregado de relações sociais" (VIGOTSKI, 2000, p. 35), o autor elabora a ideia de que as funções psíquicas, denominadas à época como superiores - percepção verbalizada, atenção voluntária e orientada, memória mediada, imaginação, linguagem, pensamento generalizado, conceptualização -, são relações sociais internalizadas e argumenta que o desenvolvimento de cada indivíduo se encontra intrinsecamente entretecido ao desenvolvimento histórico da humanidade. Parte, assim, do pressuposto de que o homem age sobre meio social, produz instrumentos técnicos e semióticos que afetam o próprio comportamento, mediam e constituem o funcionamento psíquico. No processo de significação, ou seja, de criação, apropriação e uso de signos e sentidos (VIGOTSKI, 1995), possível nas relações humanas e nas formas de atividade 
historicamente produzidas, novas formações psíquicas podem emergir, ampliando os modos de agir, de pensar, de participar da cultura.

Em seus estudos acerca da deficiência, Vigotski (1997) adensa o pressuposto acima explicitado ao se aproximar do debate sobre a compensação. Em seu esforço de reelaborar o conceito, reitera a natureza social do desenvolvimento e as possibilidades de humanização na condição de lesão orgânica, enfatizando a dinamicidade dos processos psíquicos afetados pela cultura (DAINEZ; SMOLKA, 2014). Realça-se, nessa discussão, o argumento de que conhecer a especificidade da condição orgânica é fundamental para se criar caminhos de um trabalho educacional orientado para novas formações psíquicas no processo de desenvolvimento cultural do indivíduo (DAINEZ, 2017).

Consideramos, então, que os estudos de Vigotski (1995, 1996, 1997, 2000) se apresentam de maneira pertinente e propositiva na contemporaneidade pelo modo de conceber a deficiência, a educação, o desenvolvimento e de colocá-los em relação interconstitutiva. Ou seja, esse autor problematiza a deficiência ou a lesão orgânica como uma condição de desenvolvimento profundamente afetada pela dinâmica social e histórica, podendo ser transformada nas/pelas relações e condições de produção de conhecimento, de práticas, de tecnologias.

A confluência das reflexões de Jannuzzi $(1985,2006)$ com o pensamento de Vigotski (1995, 1996, 1997) apresenta-se no modo como ambos sensibilizam-se com o potencial do gesto educativo na condição de lesão orgânica e como argumentam pela premência de uma transformação das condições de ensino. Além disso, clamam por formas de organização da sociedade orientada por uma ética sócio-política pautada na justiça e na igualdade social, a fim de ancorar a participação efetiva de todos e de cada indivíduo nas práticas e atividades culturais.

É a partir dessas considerações que problematizamos a função social da escola no contexto da atual política de educação inclusiva. Temos, assim, como objetivo neste estudo analisar as relações de ensino e os processos de escolarização de alunos com deficiências, levantando, com isso, questionamentos acerca do funcionamento e da função da escola. Para o propósito deste artigo, os sujeitos desse processo são dois alunos com diferentes condições orgânicas - síndrome de Angelman e deficiência múltipla; síndrome de Down e deficiência intelectual -, inseridos em diferentes turmas.

Colocar esse objetivo significa buscar compreender os avanços e enfrentar os desafios que persistem na contemporaneidade a respeito da educação escolar de crianças com deficiência para, então, problematizarmos acerca do que estamos esperando da escola com relação ao modo de acolher - incluir? - esses alunos.

\section{Educação escolar de alunos com deficiências na contemporaneidade: avanços e desafios}

No atual momento histórico, em que constatamos muitos esforços no sentido de projetar as transformações das condições existentes de acesso, permanência e progressão na escola pública, é preciso destacar conquistas que se tornaram possiveis em meio às arenas de lutas que marcam o campo da educação em geral, e da educação especial em particular. 
Podemos pontuar, primeiramente, o movimento de formação e ampliação do direito educacional/escolar a essa população: a identificação da criança excepcional ${ }^{3}$ como aluno do sistema geral de educação, regulamentada pelas disposições da LDBEN n.4.024/61 (BRASIL, 1961); a determinação de tratamento especial a esses alunos, amparado pela Lei no 5.692/71 (BRASIL, 1971); o entendimento da Educação Especial como modalidade da educação escolar e sua oferta como dever constitucional do Estado, garantida desde a Educação Infantil na LDBEN n. 9.394/96 (BRASIL, 1996). Essas mudanças levaram ao aumento das matrículas desses alunos em escolas regulares públicas, de modo que, a partir de 2008, a porcentagem de alunos com deficiências matriculados em classes comuns passou a ser maior que a desses alunos em classes e escolas especiais (CASTR0; DALL'ACQUA, 2013).

Embora com ambiguidades e inúmeros problemas denunciados pela literatura específica (PASCHOALICK, 1981; FERREIRA, 1993), as políticas públicas foram assumindo a educação da criança com deficiência. Ao compreendermos, no entanto, que a escola pública "deve ter como seu ponto de partida e de chegada os sujeitos históricos concretos na totalidade histórica de suas condições” (FRIGOTTO, 2005, p. 248), somos levados a indagar: Como consolidar a educação escolar pública dos alunos com deficiência? Quais são as condições em que a escola os recebe, uma vez que o fato de estarem dentro dela não significa que estão efetivamente sendo contemplados e tratados como sujeitos de direitos, como sujeitos da educação (SIEMS-MARCONDES; CAIADO, 2013)?

Os desafios impõem-se quando, segundo Kassar (2011), devido à escolha de programas que indicam se pautar por restrições de investimento, contamos com a oferta de uma única forma de atendimento aos alunos com deficiência, que não dá conta de atender as diversas demandas e características; e, quando trabalhos como os de Garcia (2008) e Pletsch (2010) apontam para as tensões produzidas no cotidiano escolar frente às condições de implementação de uma política educacional global. Um estudo como o de Laplane (2014) chama, ainda, a atenção para o fato de que, embora o conjunto de recursos de apoio à escolarização tenha se expandido com as políticas de educação inclusiva, ainda não se garante o sucesso desses alunos no sistema de ensino.

Também merecem ser destacados no trabalho de Laplane (2014) os dados sobre os tipos de deficiência presentes na educação básica, os quais indicam que a deficiência intelectual concentra a maior quantidade de matrículas e segue como o maior desafio em termos de acesso ao conhecimento escolar.

Neste caso, indagamos: Como conceber a função dessa instituição social quando entendemos que as possibilidades de desenvolvimento da criança com deficiência estão intrinsecamente relacionadas ao ato/atividade de ensinar; e quando compreendemos a articulação entre as possibilidades de humanização e a responsabilidade social? Enfim, como concebemos a educação escolar: como processo de socialização? Como transmissão de conteúdos? Como lócus de desenvolvimento cultural? De formação social da mente? E como concebemos socialização, desenvolvimento, ensino, atividade mental?

3- Termo utilizado pela legislação. 
Com essas problematizações, remetemos a dois casos de alunos com diferentes deficiências em processo de escolarização, chamando a atenção para os modos peculiares de participação nas práticas educacionais, para a condição escolar, para as relações de ensino, para as possibilidades de desenvolvimento.

\section{Procedimentos metodológicos}

Ao considerarmos a íntima relação teoria e prática, a dimensão da práxis como lócus potencializador da produção do novo, ressaltamos a dimensão transformativa do método na perspectiva histórico-cultural. De acordo com Stetsenko (2016), no âmago dessa orientação metodológica manifesta-se a dimensão onto-epistemológica imbricada com uma ética sócio-política que desafia a ideologia de adaptação e controle, pautando-se na transformação social.

Neste sentido, partimos do pressuposto de que a produção de conhecimento científico é uma atividade humana cujo empreendimento tem valor histórico e implicação social. A produção de conhecimento apresenta-se, assim, articulada com a construção de novas formas de vida e práticas sociais.

Temos em vista que, a partir da perspectiva histórico-cultural, pensar na singularidade de dois casos de alunos, nas suas histórias e situações de escolarização, contribui para evidenciar tensões e aspectos não óbvios ou negligenciáveis da realidade educacional, contribuindo com a discussão de problemáticas que incidem na formulação de políticas públicas educacionais.

Como já anunciamos acima, a pesquisa de campo aconteceu em uma escola pública do ensino fundamental da rede municipal de uma cidade localizada no Estado de São Paulo. Acompanhamos dois alunos, com diferentes deficiências e em diferentes turmas, semanalmente no ano de 2010 e, de forma mais esporádica, nos anos de 2011 e 2012.

Durante o acompanhamento, procedemos de modo a realizar registros escritos em diário de campo e videogravados. Essas duas formas de registros usadas de maneira articulada tornam possíveis certas formas específicas de lembrar, de retornar às cenas e reconstruir os fatos vividos, de conduzir a análise; implica um trabalho de transcrição, narração e comentários de detalhes, do dito e não dito nas/pelas palavras e nos/pelos gestos - olhares, expressões, movimentos corporais, ações.

Esse modo de investigar requer um constante exercício de olhar, de escuta, na tentativa de compreensão do ponto de vista do outro (FREITAS, 2003). Nossa intenção como condição de investigação foi de intensa participação nas práticas escolares, buscando vivenciar as interações cotidianas e delas nos distanciando na procura de analisar e dar visibilidade à dinâmica das relações interpessoais, institucionais.

Para proceder às análises do material empírico, inspiramo-nos na proposta do método construtivo tal como proposto por Vigotski (1996, 2000), assumindo que aquilo que emerge como possíveis categorias analíticas não se encontram estabelecidas a priori, mas se constroem no processo mesmo de investigação. 0 trabalho analítico interpretativo baseia-se na constante problematização e articulação da teoria e da empiria, o que nos levou a escolher e a privilegiar no contexto escolar situações vividas que permitissem 
observar, registrar e acompanhar detidamente movimentos, gestos, dizeres, na dinâmica das interações, atentando para os modos singulares de participação dos sujeitos nas práticas escolares.

\title{
Os sujeitos e as condições de escolarização: focalizando os modos de participação nas práticas educacionais
}

\section{0 caso de um aluno com síndrome de Down e deficiência intelectual na escola}

Gustavo apresenta síndrome de Down e deficiência intelectual. Comunica-se, sobretudo, por uso de gestos e de algumas poucas palavras isoladas como "não", "meu", além de emitir vocalizações e se expressar por meio de várias expressões faciais.

0 aluno entrou na escola em 2007, no $1^{\circ}$ ano, com 7 anos, foi aprovado para o $2^{\circ}$ ano em 2008 e, no ano de 2009, passou para o $3^{\circ}$ ano, mas ficou na situação de aluno ouvinte em uma turma do $2^{\circ}$ ano. Em 2010, quando chegamos à escola, estava frequentando o $4^{\circ}$ ano em uma turma de 35 alunos.

\begin{abstract}
Ao longo desse ano foram várias as situações difíceis vivenciadas: o aluno passava pelas carteiras derrubando os materiais escolares dos colegas; fugia da sala de aula e entrava em outras salas, inclusive na sala da direção e dos professores; se jogava no chão, gritava, beliscava os colegas e a professora. A professora frequentemente trancava a porta da sala com a chave na tentativa de manter o aluno na sala de aula. Também ouvimos e registramos falas de professores e gestores como: "Ele está sendo o aluno problema da escola"; "É muito difícil segurar ele dentro da sala de aula"; "Ele tem dificuldade de obedecer regras". (Condensados Registros Diário de Campo e Videogravação, 2010).
\end{abstract}

Essas falas e gestos nos dizem sobre o lugar que o aluno vai ocupando na trama das relações e que indicam a direção segundo a qual está sendo orientada a ação pedagógica manter o aluno com deficiência na sala de aula -, responsabilidade atribuída à professora e dela cobrada institucionalmente.

Diante de situações de conflito com o aluno, a professora do $4^{\circ}$ ano questionava-se em relação às regras escolares e acreditava na relevância de Gustavo estar na escola para a socialização:

Talvez para ele na escola o que seja mesmo importante é se socializar, a convivência com os colegas, então por que não deixar ele ir para outras salas de aula, andar pela escola livremente? (Registro Diário de Campo 07.05.2010).

Podemos notar como o discurso da socialização, incorporado pela professora, ao mesmo tempo pressupõe e justifica a impossibilidade de o aluno com deficiência apropriarse das normas institucionais e participar da/na produção do conhecimento.

No entanto, contraditoriamente, deparamo-nos com outros modos de participação do aluno nas situações de ensino. 
Situação: A proposta foi planejada pela professora de educação especial da escola e pela professora da turma. Tratava-se de um projeto referente à cidade onde a escola está localizada. Dentre as atividades estavam: pesquisar pela internet e por jornais a história da cidade, elaborar em grupo cartazes com diversos temas referentes à cidade - rodovias principais, pontos turísticos... - , apresentá-lo para a turma.

$\mathrm{Na}$ apresentação dos grupos sobre os diversos temas que compõem a cidade, Gustavo filma as apresentações, focalizando os cartazes. É importante dizer que a apresentação do seu grupo foi num dia anterior, em que a pesquisadora não estava presente na sala de aula. Pelos relatos da professora de educação especial, o aluno apresentou com o grupo o cartaz, de modo a apontar as figuras e os outros integrantes do grupo e as professoras nomeavam e faziam comentários sobre os objetos que o aluno se referia.

(...)

Na continuação da aula, as professoras apresentam para a turma o percurso da escola, passando pela cidade, país até chegar ao planeta Terra e, depois o movimento inverso, do planeta Terra para a escola, usando o instrumento Google mapa. Gustavo, à medida que as professoras comentam sobre o planeta Terra, olha para a pesquisadora, aponta para o telão "Óóó". A pesquisadora olha para ele e em seguida para o telão, diz "É o planeta Terra!". Gustavo sorri e faz um gesto com as duas mãos representando o formato de uma esfera e pronuncia o som "Té". A professora, atenta ao diálogo, diz "É, é redondo". Manuseando o Google mapa, a professora de educação especial chega ao Estado de São Paulo e solicita que um aluno vá até a lousa e localize a cidade de Campinas. Um aluno se levanta, vai até o telão e mostra a cidade de Campinas. Gustavo, observando o colega, também se levanta e vai até o telão. A professora pergunta "Onde você acha que está Gu? Mostra pra mim onde você acha que está a cidade de Campinas?”. Gustavo olha atentamente para o telão que focaliza as cidades do Estado de São Paulo no mapa do Brasil. Nesse instante outro aluno também se aproxima e aponta para o lugar em que se situa a cidade. Gustavo observa e aponta para o mesmo lugar. A professora diz “Tá. Agora senta. Quem mais?”. Gustavo sorri e faz sinal de joia para a câmera.

(...)

Em outro momento, a professora de educação especial passa um slide com fotos dos principais pontos comerciais, turísticos e de lazer da cidade. Gustavo senta-se ao lado da professora da turma. A professora de educação especial mostra o planeta Terra e a professora da turma comenta com Gustavo sobre o planeta. 0 aluno aponta para o slide e faz movimento rotatório com o dedo. A professora da turma responde: "É isso mesmo, o planeta Terra", executa o mesmo movimento realizado pelo aluno. A professora de educação especial mostra a foto do campo de futebol e explica sobre a localização. Gustavo aponta para a foto e faz movimento com os pés, como se estivesse chutando uma bola. A professora da turma diz "É isso mesmo, o campo de futebol Gu". A aula prossegue. (Condensados Registros de Diário de Campo e Vídeogravação 18.08.2010).

Nesta situação, a atividade torna-se significativa para o aluno e o modo de envolvimento é potencializado. A convocação das professoras em relação a Gustavo altera-se: não é necessário mais trancar a porta para que o aluno permaneça na sala de aula. 0 modo dele comportar-se e participar da dinâmica social da aula transforma-se. 0 aluno impossível torna-se possível; o aluno que atrapalha passa a colaborar; o aluno que 
não compreende o dizer do outro passa a agir de maneira a coincidir com a orientação das professoras, ou seja, por meio de uso de gestos indicativos e representativos ele se insere na dinâmica de enunciação de forma a atingir o desejável em termos de uma atitude escolar. 0 aluno apresenta um trabalho, filma a apresentação do colega e orienta o foco da câmera para o produto em pauta - o cartaz -, vai à lousa quando a professora solicita e retorna ao seu lugar. Participa do movimento interativo de aula de maneira a cooperar e a contribuir com a realização compartilhada da atividade de instrução.

Vemos como o aluno, que não obedecia às regras, pode se apropriar delas e, com isso, muda a forma de conduta, a dinâmica afetivo-intelectual-volitiva se redimensiona desinteresse/interesse, desafeto/afeto, indisposição/disposição, produção de novos sentidos e de novas relações com o conhecimento. Lembramos que nas análises dos experimentos de Vigotski (1997), que visavam a investigar as possibilidades de desenvolvimento da criança durante a solução de tarefas, um dos pontos ressaltados é o sentido da atividade, o qual é fundante de toda a força e da dinâmica do impulso afetivo e do pensamento cognitivo vinculado à atividade prática. A mudança na posição social incide na dinâmica afetiva-volitiva que influi na dinâmica intelectual e transforma o sentido da vivência.

Chamamos atenção para o gesto do aluno referenciando-se ao movimento rotatório do planeta Terra como um indicador da possibilidade de compreensão. 0 gesto do aluno, sustentado pelo gesto de ensinar e significar da professora - "É isso mesmo, o planeta Terra" - que nomeia o referente, indica e ancora modos de compreensão via processo de significação na dinâmica da atividade.

Destacamos a postura da professora, a forma como acolhe os modos de participação do aluno, mantendo o gesto de ensinar, atribuindo sentido às ações do aluno, estando esse orientado pela crença nas possibilidades de desenvolvimento. Apontamos, assim, para a atitude pedagógica de considerar a contribuição de cada aluno na atividade coletiva.

No ano de 2011, no $5^{\circ}$ ano, Gustavo prossegue com a mesma turma. A professora é outra. Essa, ao observar o interesse do aluno por equipamentos como computador, retroprojetor, datashow, câmeras, assim como livros, passa a usá-los com mais frequência nas aulas.

A professora propõe um trabalho em grupo, em que cada grupo elegeria um poema, recitaria para a turma, registraria no caderno e depois, na lousa, teria que escrever em um quadro o nome do grupo, o poema e o autor do poema. 0 registro do poema no caderno de Gustavo é feito pela professora. No momento em que cada representante dos grupos se dirige à lousa, Gustavo também vai. Alguns alunos levam o caderno como suporte para olhar e poder lembrar o nome do poema e do autor para então escrever na lousa. Gustavo também leva o seu caderno. Observa os seus colegas e por meio de garatujas faz como se estivesse copiando algo do seu caderno e escrevendo na lousa. (Condensados Registros de Diário de Campo e Videogravação 27.06.2011).

Um dos aspectos que nos chama a atenção é a ação da professora em anotar no caderno de Gustavo o poema que o grupo dele estava trabalhando. Ela faz pelo aluno aquilo que ele ainda não consegue fazer. Lembramos aqui do tão difundido conceito de zona de desenvolvimento proximal/iminente elaborado por Vigotski (2006) que denota a 
indeterminação do processo e a abertura para novas possibilidades. E o aluno percebe ter o registro como os outros. Nessas condições, produz-se o gesto do aluno em imitar as ações dos colegas e tentar registrar o poema escrito em seu caderno na lousa. Considerando a imitação como uma forma de apropriação, essa situação indica-nos a possibilidade de novas formações que podem emergir no trabalho com o conhecimento. Embora não demonstre o domínio das letras, o modo de Gustavo se envolver na atividade mostra-nos como ele ocupa o lugar de aluno e incita-nos a pensar na criação de vias que ampliem as possibilidades de sua participação no trabalho de leitura e escrita.

Entretanto, mudam-se as condições de escolarização e os modos de participação do aluno com deficiência quando, no ano de 2012, ele foi promovido para o $6^{\circ}$ ano. Ressaltese que sua promoção ao longo do percurso escolar se deu pelo critério idade-série e da socialização com pares da mesma faixa etária. Embora a mãe, a professora da turma e a professora de educação especial argumentassem a favor de se manter Gustavo no $5^{\circ}$ ano, o fato de haver outros alunos do mesmo ano com indicação de reprovação excedia o percentual permitido pela rede de ensino, o que levou o Conselho de escola à decisão de promover o aluno com deficiência. Assim, evidencia-se a concepção de deficiência na escola que ancora as decisões e as ações administrativas: a concepção do aluno que, aprovando ou reprovando, não tem condições de aprender, e cuja retenção não faria diferença face a outros casos em pauta. A decisão de caráter administrativo evidencia, ainda, como funciona a política de inclusão: difíceis de serem efetivamente incorporados nas práticas cotidianas, e diante das estatísticas e dos critérios de avaliação, os casos de deficiência tornam-se, contraditoriamente, um álibi conveniente para a escola, que se vê sem condições de atender às necessidades específicas de cada criança, e produz, mais uma vez, os excluídos do interior (BOURDIEU; CHAMPAGNE, 2010).

Diante das novas demandas impostas pelas formas de organização e estrutura escolar - de um lado com professores polivalentes (MICHELS, 2011; VAZ; GARCIA, 2016) e, por outro, com a existência de diferentes demandas, o aluno passa a conviver com nove docentes de diversas disciplinas, com focos, procedimentos e expectativas diferenciadas, e que têm poucas informações e conhecimento sobre o caso - Gustavo reage da seguinte forma: grita, bate, tem expressões de cólera, senta-se no chão e se recusa a levantar, foge da sala de aula, perambula pela escola, teima em não tirar a mochila das costas, acaba passando a maior parte do tempo sentado junto ao portão da escola conversando com o guarda. A reação dos professores vai sendo a de conter o aluno, trancar a sala de aula, correr atrás dele, tirá-lo a força dos lugares não permitidos, e quando nem isso é possível, deixá-lo, sim, no portão da escola conversando com o guarda. No período acompanhado, constantemente, a família foi chamada pela escola para buscá-lo antes do término da segunda aula. Diante dessas condições, decide retirá-lo da escola, levando-o a frequentar uma instituição especializada, de cunho filantrópico.

\section{0 caso de um aluno com síndrome de Angelman e deficiência múltipla na escola}

Alan apresenta deficiência múltipla por sequela de uma patologia genético-neurológica, denominada síndrome de Angelman. Algumas características são: deficiência 
intelectual severa, incapacidade de falar, comprometimento físico acompanhado por movimentos desconexos e, quando possível, andar atáxico com desiquilíbrio. A síndrome também acarreta um quadro convulsivo bastante intensificado. No caso de Alan, são altas as dosagens de medicamentos para controle de convulsões, o que aumenta o estado de sono. Ele é usuário de cadeira de roda com colete e uma mesa acoplada. Não tem uma forma de comunicação estabelecida.

0 aluno frequenta a mesma escola desde 2006. No ano de 2010, estava com 11 anos de idade no $5^{\circ}$ ano, uma turma formada por vinte e oito alunos. Do mesmo modo que o caso de Gustavo, o aluno tem sido aprovado sem ter alcançado o conhecimento ou habilidades necessárias esperadas com as atividades de ensino-aprendizagem em relação aos respectivos anos. Frente a isso, indagamos sobre o que esse aluno faz em um $5^{\circ}$ ano, o que é possível fazer com ele e o que a escola tem feito?

Conversando com a professora de educação especial da escola e lendo os relatórios da equipe de profissionais fornecidos para a escola no ano de 2006, vimos que as indicações de trabalho com Alan eram: massagens e estímulos sensitivos, sonoros e visuais. Perguntamos sobre o trabalho de linguagem e a professora de educação especial da escola relatou que essa não era uma questão investida no âmbito escolar, pois os profissionais, citados, em um dos relatórios, forneceram a informação de que haviam desistido de realizar o trabalho de Comunicação Aumentativa e Alternativa com Alan, devido aos seus graves impedimentos orgânicos que o inviabilizavam de compreender e dar uma resposta. (Registro Diário de Campo, 12.04.2010).

A recomendação de trabalho com Alan na escola foi dada, na forma de relatórios, pelos profissionais dos serviços de educação e de saúde que ele já frequentava em uma instituição especializada. A indicação que prevalece é o trabalho de estimulação sensório-motora.

Na escola, o desconhecimento do que e de como fazer com um aluno com graves deficiências múltiplas, a descrença no potencial da educação frente às condições orgânicas em questão, as marcas da razão médica historicamente construída acerca da pessoa com deficiência (JANNUZZI, 2006), a falta de recursos materiais e humanos para realizar outra forma de trabalho levam, então, a apropriação das recomendações dos especialistas e marcam as condições de produção da vivência de Alan nesse espaço social. A orientação do trabalho escolar com esse aluno confirma-se nas fichas de avaliação do aluno:

[Alan] Tem interesse por objetos sonoros e acompanha dentro do seu campo visual (Ficha de Avaliação Descritiva Anual do 4º. Bimestre do ano de 2006).

Seu desenvolvimento é bastante limitado, por isso as atividades são restritas, específicas, individualizadas e voltadas às suas necessidades. Neste bimestre o objetivo foi despertar seus cinco sentidos por meio de materiais e brinquedos, coloridos, ásperos e lisos, tentando aumentar seu campo visual (Ficha de Avaliação Descritiva Anual do 3 Bimestre do ano de 2007). 
0 trabalho realizado é através de estímulos sonoros dentro do seu campo visual (Ficha de Avaliação Descritiva Anual do $1^{\circ}$. Trimestre do ano de 2008).

É possível notar, a partir desses documentos, que as atividades de estimulação vigoraram e foram se estabilizando como práticas pedagógicas ao longo da permanência do aluno na escola. 0 objetivo educacional escolar em relação a esse aluno é desviado pelos serviços terapêuticos e reduzido à estimulação sensório-motora. Em outros termos, persiste o desafio, no campo da educação, de se reconhecer e assumir o trabalho educacional - que implica possibilidade de desenvolvimento cultural e humanização - com crianças com grave condição orgânica; uma luta histórica como vimos nas obras de Pessotti (1984), Jannuzzi (1985), Mazzotta (1987).

Como enfatiza Vygotsky (1995), o desenvolvimento cultural, a história pessoal entretecida na e pela história geral dos homens, leva-nos inescapavelmente aos problemas da educação; sendo a educação formal um direito fundamental, uma via de acesso, socialmente instituída, da constituição do saber humano em saber da criança (PINO, 2000).

A respeito da história de vivências desse aluno no $5^{\circ}$ ano, destacamos falas da sua professora:

O Alan está sendo uma descoberta para mim. [...]. Eu o deixo no cantinho da minha mesa, porque eu preciso cuidar dele. [...]. 0 que passaram pra mim é cuidar, fazer massagens e trocas sensitivas. [...]. Ele fica com o chocalho que faz som. [...]. Ele não dá trabalho, se deixar ele fica a aula inteira dormindo. Mas, eu não sei se é assim que eu devo fazer. [...]. Muitas vezes ele tem um olhar perdido que é difícil imaginar no que ele está pensando. Mas, é interessante que quando fala o nome dele ele já olha. (Registro Diário de Campo, 29.03.2010).

No discurso da professora, ao mesmo tempo em que se apresenta a reiteração das práticas de estimulação e cuidado, percebemos que ela se indaga sobre o que fazer com esse aluno. A suspeita de que Alan pode responder, o desconforto em relação ao seu modo de participação - dorme muito ou se encontra em estado sonolento; quando acordado, balança um chocalho que produz som; apresenta uma atenção dispersa, fixando o olhar para um ponto da parede durante um tempo considerável - e as incertezas de como trabalhar com ele, levam a professora a buscar outras formas de interação e intervenção educacional. Ela passa a realizar um trabalho de interpretação dos movimentos e expressões do aluno, atribuindo sentido e nomeando as ações: sorriso de alegria/saudades/graça/ gostar, sono, gesto de tchau, sede, dor, orientação do olhar, postura corporal/sustento de cabeça e de tronco para olhar em direção ao outro ou à atividade na lousa, ao caderno de um aluno ou ao livro lido pela professora. Ademais, a professora começou a: conversar com Alan sobre as situações vividas na aula; orientar e manter a sua atenção para o que estava sendo trabalhado com a turma; solicitar que os alunos mostrassem as produções para ele; colocá-lo sentado em grupo, em dupla, sentar-se ao lado dele, andar com ele na cadeira de rodas pela sala passando pelas carteiras dos colegas para olhar e conversar sobre as atividades realizadas. 
0 objetivo de estimular vai sendo redimensionado pelo objetivo de significar e, com isso, muda o lugar da ação, o aluno não só recebe, mas expressa, interage, participa mais ativamente na dinâmica das interações. Formas de significar o mundo vão se tornando possíveis na relação aluno-professora-conhecimento. 0 modo de ele responder na interação é realçado e intensificado. Com isso, muda inclusive o lugar físico ocupado pelo aluno na sala de aula; ele não fica apenas ao lado da mesa da professora para receber cuidado.

No ano de 2011, o aluno foi promovido para o $6^{\circ}$ ano, adoeceu por ficar muito tempo sentado na mesma posição, sem mudança de decúbito, e fez uma cirurgia. Devido ao acontecido, teve uma frequência esporádica durante o ano letivo. Mesmo assim, foi aprovado para o $7^{\circ}$ ano.

Durante as nossas idas esporádicas à escola ao longo dos anos de 2011 e 2012, conversamos com alguns professores dos $6^{\circ}$ e 7 o anos. A professora de Língua Portuguesa comenta "Eu não sei o que o Alan tem. Ninguém me passou nada. É uma Síndrome?”. 0 professor de Matemática conta "Disseram que ele não compreende nada, né? Não fala, não interage com as pessoas. (...). Que é pra deixar ele quieto e ficar de olho se ele não afoga”. (Registro Diário de Campo, 29.04.2012).

Desconhecendo a síndrome e a história de Alan na escola, sem informações e formação para atender às novas demandas que se impõem, os professores desse Ciclo, $6^{\circ}$ e $7^{\circ}$ anos, demonstram as dificuldades de trabalho com o aluno; o qual permanece em sua cadeira de rodas, no fundo da classe. Sem qualquer condição de acompanhamento da atividade escolar, Alan volta a dormir na sala de aula, sendo que, inclusive, o trabalho de estimulação é deixado de lado. A única recomendação para os professores é que se atentem para que ele não engasgue e não se afogue.

Ainda, na Ficha de Avaliação Descritiva Anual do ano de 2007, quando Alan estava no $3^{\circ}$ Ano, encontramos o seguinte registro:

Sua inclusão foi fundamental para o seu desenvolvimento e de todos nós, que com ele aprendermos a sermos mais pacientes, mais cuidadosos, que cada um tem seu jeito e seu tempo de aprender e, principalmente, a respeitarmos as diferenças. A convivência com Alan [...] nos tornou seres humanos melhores.

Deste ponto de vista, a presença de Alan na escola justifica-se pela sua convivência com os outros e dos outros em relação a ele e, independentemente do modo como ele participa nessa dinâmica, considera-se que esse aluno está exprimindo o máximo de sua capacidade, a qual deve ser respeitada. Todos aprendem a não discriminar, a aceitar e a respeitar a diferença, a valorizar cada pessoa, a conviver dentro da diversidade humana, a serem mais cooperativos, metas essas que têm suas importâncias. Contudo, os resultados dessa prática de socialização mostram-se extremamente frágeis e inespecíficos com relação ao trabalho educativo e ao desenvolvimento de Alan, como aluno no contexto escolar.

Para além da socialização e da estimulação, vimos que muito mais pode ser realizado com esse aluno em termos de ação pedagógica e de desenvolvimento cultural. E isso faznos repensar as condições de acolhimento educacional e a definição de políticas públicas. 


\section{Discussões e considerações}

Quando Vygotsky (1997) argumenta que os objetivos educacionais em relação às crianças com deficiência precisam ser os mesmos para as crianças tidas como normais, ele se ancora nas leis gerais do desenvolvimento cultural. Não se trata, portanto, de reduzir as expectativas em relação ao processo de ensino e aprendizagem, tampouco, de ignorar as especificidades da condição orgânica e idealizar a deficiência, admitindo que todos podem aprender tudo ou qualquer coisa, em determinado tempo/momento, desconsiderando as condições e a história de cada pessoa.

A forma como esse autor refere-se aos objetivos educacionais diz respeito às ações que devem ser orientadas para o potencial do processo de humanização, sem o estabelecimento de limites a priori e sem tomar como ponto de partida a falta, embora (re) conhecendo as condições e peculiaridades das lesões. Essa forma de conceber o trabalho educacional implica atenção aos modos de participação da criança com deficiência nas práticas sociais e, em especial, à significação das ações mediadas que se produzem na dinâmica das relações. Assim, a questão que se evidencia é como considerar no trabalho de mediação pedagógica as especificidades da deficiência tendo como horizonte as possibilidades de desenvolvimento cultural, uma vez que a condição orgânica não é impeditiva da ação educacional.

Salientamos aqui uma diferença fundamental nos modos de se conceber a dimensão social: por um lado, se tomamos o desenvolvimento como acontecimento de natureza individual, a socialização é vista como um objetivo a ser atingido: o indivíduo se abre para a convivência social na interação com os outros, vai aprendendo a conviver, vai se tornando cada vez mais socializado; por outro lado, assumindo-se a natureza social do desenvolvimento humano, a dimensão social é condição de realização, ou seja, o social ganha uma dimensão mais ampla que condensa a história de produção e relação humana, tornando-se lócus de constituição do desenvolvimento individual e coletivo. Se entendermos que "a história do indivíduo está fortemente condicionada pela história de seu meio" (PINO, 2000, p. 59), pensamos não na socialização das ações individuais, mas na tensão da constituição social dessas ações, na apropriação dos signos, sentidos, artefatos produzidos nas relações e no modo como esse processo de significação afeta e impulsiona a emergência de novas formações psicológicas, o que torna possível transpor os limites orgânicos.

Falar de constituição social do indivíduo é, portanto, diferente de falar em socialização das ações individuais, e demanda outras implicações educacionais. Com base nisso, argumentamos que a função social da escola não se resume à socialização/ convivência; relaciona-se, sim, ao trabalho de ensino e à apropriação do conhecimento valorizado, condição de desenvolvimento cultural orientador da personalidade.

Libâneo (2012) analisa as políticas educativas do Banco Mundial assumidas pelo Brasil a partir dos acordos internacionais e mostra que, sob a ótica de premissas pedagógicas humanistas através das quais se manifestam critérios econômicos, estabelece-se o diagnóstico da homogeneidade, do autoritarismo, da discriminação e da exclusão atrelado ao modelo tradicional de escola. Com isso, em nome de uma educação inclusiva, que visa 
ao atendimento às diferenças individuais, a escola passa a cumprir função assistencial de convivência entre diferentes. Tomando como eixo do desenvolvimento humano as necessidades mínimas de aprendizagem, essa abordagem economicista e tecnicista da educação coloca em segundo plano o direito ao conhecimento e o papel da mediação pedagógica no processo de ensino-aprendizagem. Nas palavras do autor:

[...] as políticas de universalização do acesso acabam em prejuízo da qualidade do ensino, pois, enquanto se apregoam índices de acesso à escola, agravam-se as desigualdades sociais do acesso ao saber, inclusive dentro da escola. (LIBÂNEO, 2012, p. 23).

As consequências no funcionamento interno na escola são visíveis nos dados que discutimos neste artigo. $\mathrm{Na}$ análise dos casos, notamos como a função que a escola vai assumindo em relação aos alunos com deficiência traz a repercussão do discurso médico/ estimulação, as marcas do trabalho assistencialista/cuidado, os ecos de um modo de conceber a inclusão escolar/socialização; e como isso impacta o processo de escolarização dos alunos, afeta as relações de ensino.

As histórias de aprovação escolar de Gustavo e Alan ancoraram-se no argumento da idade, da necessidade de se socializar com alunos da mesma faixa etária e na suposição de melhor aproveitamento da situação de reprovação por alunos que teriam, em princípio, condições de adquirir os conteúdos escolares. Os alunos com deficiência são aprovados não pela condição de conhecimento e sim de desconhecimento e impossibilidades pressupostas pela escola. Como vimos, Gustavo retorna, inclusive, para a instituição especializada. Alan, embora continue na escola até se formar no $9^{\circ}$ ano, passa a frequentar apenas duas aulas durante dois dias na semana e volta a ficar em estado sonolento e com a atenção dispersa na maior parte do tempo.

0 desfecho do processo de escolarização do aluno Gustavo faz-nos indagar ainda a respeito do lugar das instituições especializadas que, embora na legislação sejam apresentadas enquanto serviços de apoio, complementar ou suplementar, continuam recebendo e assumindo o aluno que o setor público não dá conta de acolher para assegurar um processo de ensino significativo. Novamente, seja diante da função socializadora da escola inclusiva, seja diante do ensino homogêneo de conteúdos circunscritos em disciplinas fragmentadas, o aluno com deficiência parece continuar tornando-se responsabilidade de instituições especializadas filantrópicas e assistencialistas. A escolha da família, frente à ausência de opções, merece ser destacada não como uma opção individual, mas como um grave problema de política pública de educação.

A investigação das situações vividas no cotidiano escolar levam-nos a chamar a atenção para as especificidades de cada caso na sua singularidade. Vemos o quanto o aluno Gustavo pôde responder positivamente à situação de ensino e como nos faz pensar nos muitos modos de compreensão e possibilidades de conceitualização, na criação de novas vias de ensino-aprendizagem, viabilizando a sua participação nas mais diversas formas de atividades humanas. Também, diante da dependência radical da condição de Alan, é possível ressaltar a importância da posição do outro na significação e mediação constante de suas ações. Diferentes especificidades e modos de participação nos indicam, 
portanto, a possibilidade de trabalho educacional e de desenvolvimento cultural que pode ser vislumbrado socialmente, mas em condições escolares adequadas.

No nosso trabalho investigativo na escola, na vivência com professores e alunos, podemos dizer que são imensos os desafios que se colocam quando levamos em conta o trabalho com o conhecimento acumulado na história de produção humana. A formação e a atualização do professor, a atividade de ensino e pesquisa envolvendo escolauniversidade, as turmas com menor número de alunos, o vigor do coletivo de trabalho na escola, a organização do trabalho pedagógico considerando as especificidades e projetando possibilidades de participação de cada aluno no processo de ensino e aprendizagem, o sentido da atividade no contexto escolar, o apoio pedagógico constante, a disponibilização e o uso de recursos diversos e atualizados são dimensões essenciais e que vêm sendo incansavelmente ressaltadas ao considerarmos a qualidade do funcionamento da escola.

Estando a atividade de ensinar/significar orientada para o desenvolvimento humano, cabe-nos criar condições efetivas de participação da pessoa com deficiência nas atividades sociais, laborais, alargando as formas de relação com o conhecimento. Mas isso demanda, sem dúvida, repensar, ressignificar a função social da escola nas condições mais abrangentes - da contemporaneidade.

\section{Referências}

ANACHE, Alexandra Ayach. Diagnóstico ou inquisição: estudo sobre o uso do diagnóstico psicológico na escola. 1997. Tese (Doutorado em Psicologia) - Universidade de São Paulo, São Paulo, 1997.

BRASIL. Lei de diretrizes e bases da educação nacional, n. 4024. Brasília, DF: MEC, 1961.

BRASIL. Lei de diretrizes e bases da educação nacional, n. 5692. Brasília, DF: MEC, 1971.

BRASIL. Lei de diretrizes e bases da educação nacional, n. 9394. Brasília, DF: MEC, 1996.

BOURDIEU, Pierre; CHAMPAGNE, Patrick. Os excluídos do interior. In: NOGUEIRA, Maria Alice; CATANI, Afrânio (Org.). Escritos de educação. 11. ed. Petrópolis: Vozes, 2010. p. 217-228.

BUENO, José Geraldo Siqueira. A produção social da identidade do anormal. In: FREITAS, Marcos Cezar de (Org.). História social da infância no Brasil. 6. ed. São Paulo: Cortez, 2006. p. 251-276.

CASTRO, Vanessa Dias Bueno; DALL'ACQUA, Maria Júlia Canazza. Matrículas de alunos público-alvo da educação especial: dados dos censos escolares entre 2008 e 2012. In: ENCONTRO DA ASSOCIAÇÃO BRASILEIRA DE PESQUISADORES EM EDUCAÇÃO ESPECIAL, 7., 2013, Londrina. Anais.... Lodrina: [s. n.], 2013. Disponível em: <http://www.uel.br/eventos/congressomultidisciplinar/pages/arquivos/ anais/2013/AT02-2013/AT02-021.pdf>. Acesso em: 02 out. 2016. p. 1173-1181.

DAINEZ, Débora. Desenvolvimento e deficiência na perspectiva histórico-cultural: contribuições para educação especial e inclusiva. Revista de Psicologia, Santiago de Chile, v. 26, n. 2, p. 1-10, 2017. Disponível em: <http://dx.doi.org/10.5354/0719-0581.2017.47948>. Acesso em: 02 out. 2016.

DAINEZ, Débora; SMOLKA, Ana Luiza Bustamante. 0 conceito de compensação no diálogo de Vigotski com Adler: desenvolvimento humano, educação e deficiência. Educação e Pesquisa, São Paulo, v. 40, n. 4, p. 1093-1108, 2014. Disponível em: <http://dx.doi.org/10.1590/S1517-97022014071545>. Acesso em: 02 out. 2016. 
FERREIRA, Julio Romero. A exclusão da diferença. Piracicaba: Unimep, 1993.

FREITAS, Maria Teresa de Assunção. A perspectiva sócio-histórica: uma visão humana da construção do conhecimento. In: FREITAS, Maria Teresa Assunção; SOUZA, Solange Jobim; KRAMER, Sonia (Org.). Ciências humanas e pesquisa: leituras de Mikhail Bakhtin. São Paulo: Cortez, 2003. p. 26-38.

FRIGOTTO, Gaudêncio. Escola pública brasileira na atualidade: lições da história. In.: LOMBARD, José Claudinei; SAVIANI, Demerval; NASCIMENTO, Maria Isabel Moura (Org.). A escola pública no Brasil: história e historiografia. Campinas: Autores Associados, 2005. p. 221-254.

GARCIA, Rosalba Maria Cardoso. Políticas inclusivas na educação: do global ao local. In: BAPTISTA, Claudio Roberto; CAIADO, Katia Regina Moreno; JESUS, Denise Meyrelles (Org.). Educação especial: diálogo e pluralidade. Porto Alegre: Mediação, 2008. p. 11-24.

JANNUZZI, Gilberta Martino. A educação do deficiente no Brasil: dos primórdios ao início do século XXI. 2. ed. Campinas: Autores Associados, 2006.

JANNUZZI, Gilberta Martino. A luta pela educação do deficiente mental no Brasil. São Paulo: Cortez: Autores Associados, 1985.

KASSAR, Mônica de Carvalho Magalhães. Percursos da constituição de uma política brasileira de educação especial inclusiva. Revista Brasileira de Educação Especial, Bauru, v. 17, n. esp. p. 41-58, 2011. Disponível em: <http://www.scielo.br/pdf/rbee/v17nspe1/05.pdf>. Acesso em: 01 nov. 2015.

LAPLANE, Adriana Lia Friszman. Condições para o ingresso e permanência de alunos com deficiência na escola. Cadernos Cedes, Campinas, v. 34, n. 93, p. 191-205, 2014. Disponível em: <http://www.scielo.br/ scielo.php?pid=S0101-32622014000200191\&script=sci_abstract\&tlng=pt>. Acesso em: 30 out. 2015.

LIBÂNEO, José Carlos. 0 dualismo perverso da escola pública brasileira: escola do conhecimento para os ricos, escola do acolhimento social para os pobres. Educação e Pesquisa, São Paulo, v. 38, n. 1, p. 13-28, 2012. Disponível em: <http://www.scielo.br/scielo.php?pid=S1517-97022012000100002\&script=sci_ abstract\&tlng=pt>. Acesso em: 01 mar. 2016.

MAZZOTTA, Marcos José da Silveira. Educação escolar: comum ou especial? São Paulo: Pioneira, 1987.

MICHELS, Maria Helena. 0 instrumental, o generalista e a formação à distância: estratégias para a reconversão docente. In: BAPTISTA, Claudio Roberto; CAIADO, Katia Regina Moreno; JESUS, Denise Meyrelles (Org.). Professores e educação especial: formação em foco. Porto Alegre: Mediação, 2011. p. 79-90.

PASCHOALICK, Wanda. Análise do processo de encaminhamento de crianças das classes especiais para deficientes mentais, desenvolvido nas escolas de $1^{\circ}$ grau da delegacia de ensino de Marília. 1981. Dissertação (Mestrado em Educação) - Pontifícia Universidade Católica de São Paulo - (PUC/SP), São Paulo, 1981.

PESSOTTI, I. Deficiência mental: da superstição à ciência. São Paulo: Edusp, 1984.

PINO, Angel. A Psicologia concreta de Vigotski: implicações para a educação. In: MALHONEY, Abigail Alvarenga et al. (Org.). Psicologia \& educação: revendo contribuições. São Paulo: Educ, 2000. p. 33-62. 
PLETSCH, Márcia Denise. Repensando a inclusão escolar: diretrizes políticas, práticas curriculares e deficiência intelectual. Rio de Janeiro: Nau: Edur, 2010.

SIEMS-MARCONDES, Maria Edith Romano; CAIADO, Katia Regina Moreno. Educação especial: da filantropia ao direito à escola. In: CAIADO, Katia Regina Moreno (Org.). Trajetórias escolares de alunos com deficiência. São Carlos, SP: EdUFSCar, 2013. p. 35-64.

STETSENKO, Anna. Vygotsky's theory of method and philosophy of practice: implications for trans/formative methodology. Educação. Porto Alegre, v. 38, p. 832-841, 2016. Disponível em: <http://revistaseletronicas. pucrs.br/ojs/index.php/faced/article/viewFile/24385/15418>. Acesso em: 20 out. 2017.

VAZ, Kamille; GARCIA, Rosalba Cardoso. 0 professor de educação especial na perspectiva da educação inclusiva: reflexões acerca da articulação entre o modelo de professor e o projeto de escola. In: REUNIÃO CIENTÍFICA REGIONAL DA ANPED. ANPED-SUL, 2017, Curitiba. Anais... Curitiba: [s. n.], 2016. p. 1-15. Disponível em: <http://www.anpedsul2016.ufpr.br/portal/wp-content/uploads/2015/11/eixo22_KAMILLEVAZ-ROSALBA-MARIA-CARDOSO-GARCIA.pdf>. Acesso em: 03 out. 2016.

VIGOTSKI, Lev Semyonovich. Manuscrito de 1929. Educação \& Sociedade, Campinas, v. 21, n. 71, p. $21-44,2000$.

VYGOTSKI, Lev Semyonovich. Obras escogidas. v. III. Madrid: Visor, 1995.

VYGOTSKI, Lev Semyonovich. Obras escogidas, v. V. Madrid: Visor, 1997.

VIGOTSKI, Lev Semyonovich. Teoria e método em psicologia. São Paulo: Martins Fontes, 1996.

Recebido em: 14.11.2017

Revisões em: 15.06 .2018

Aprovado em: 26.06.2018

Débora Dainez é doutora e pós-doutora em psicologia educacional pela Faculdade de Educação da Universidade Estadual de Campinas - (FE Unicamp). Pesquisadora de pósdoutorado do Programa de Pós-Graduação Saúde, Interdisciplinaridade e Reabilitação, Faculdade de Ciências Médicas, Universidade Estadual de Campinas - (FCM Unicamp).

Ana Luiza Bustamante Smolka é doutora em educação pela Faculdade de Educação da Universidade Estadual de Campinas - (FE Unicamp). Pós-doutora em psicologia da educação na Universidade de Clark, Mass, USA. Livre-docente pela Faculdade de Educação da Universidade Estadual de Campinas - (Unicamp). Integra o Grupo de Pesquisa Pensamento e Linguagem dessa unidade. 